\title{
Understanding liaison psychiatry commissioning: an observational study
}

\author{
Matt Fossey, Lauren Godier-McBard, Elspeth A. Guthrie, Jenny Hewison, Peter Trigwell, \\ Chris J. Smith and Allan O. House
}

\begin{abstract}
Purpose - The purpose of this paper is to explore the challenges that are experienced by staff responsible for commissioning liaison psychiatry services and to establish if these are shared by other health professionals.
\end{abstract}

Design/methodology/approach - Using a mixed-methods design, the findings from a mental health commissioner workshop $(\mathrm{n}=12)$ were used to construct a survey that was distributed to health care professionals using an opportunistic framework $(\mathrm{n}=98)$.

Findings - Four key themes emerged from the workshop, which was tested using the survey. The importance of secure funding; a better understanding of health care systems and pathways; partnership working and co-production and; access to mental health clinical information in general hospitals. There was broad convergence between commissioners, mental health clinicians and managers, except in relation to gathering and sharing of data. This suggests that poor communication between professionals is of concern.

Research limitations/implications - There were a small number of survey respondents $(\mathrm{n}=98)$. The sampling used an opportunistic framework that targeted commissioner and clinician forums. Using an opportunistic framework, the sample may not be representative. Additionally, multiple pairwise comparisons were conducted during the analysis of the survey responses, increasing the risk that significant results were found by chance.

Practical implications - A number of steps were identified that could be applied in practice. These mainly related to the importance of collecting and communicating data and co-production with commissioners in the design, development and monitoring of liaison psychiatry services.

Originality/value - This is the first study that has specifically considered the challenges associated with the commissioning of liaison psychiatry services.

Keywords Commissioning, Liaison psychiatry, Service improvement

Paper type Research paper

\section{Introduction}

Following the Lansley reforms of the National Health Service (NHS) (Roland and Rosen, 2011) and the introduction of the Care Act 2012, the role and function of bodies that commission services in the NHS has changed radically. One of the key commissioning challenges is better management of patients with co-morbid mental and physical health needs (Naylor et al., 2015; Hague and Fossey, 2012; Fellow-Smith et al., 2012). This is partly being achieved through a renewed emphasis on the importance of the delivery of liaison psychiatry services. The NHS Mental Health Five Year Forward View (FYFV) and its accompanying commissioning dashboard (NHS, 2018) sets targets for a stepped increase in acute hospital liaison psychiatry coverage to $50 \%$ by 2020/2021, and the recent NHS long term plan (NHS England, 2019) which sets ambitious targets for $70 \%$ of all acute hospital accident and emergency (A\&E) departments to have appropriately compliant liaison psychiatry services by 2023/2024 (Para 3.96). There has also been a continued momentum from practitioners and think tanks (Parsonage and Fossey,
(Information about the authors can be found at the end of this article.)

Received 26 March 2020 Revised 8 June 2020

Accepted 8 June 2020

(c) Matt Fossey, Lauren Godier-McBard, Elspeth A. Guthrie, Jenny Hewison, Peter Trigwell, Chris J. Smith and Allan O. House. Published by Emerald Publishing Limited. This article is published under the Creative Commons Attribution (CC BY 4.0) licence. Anyone may reproduce, distribute, translate and create derivative works of this article (for both commercial and non-commercial purposes), subject to full attribution to the original publication and authors. The full terms of this licence may be seen at http:// creativecommons.org/licences/by/ 4.0/legalcode

Funding. This work was undertaken as part of the liaison psychiatry: Measurement and Evaluation of Service Types, Referral patterns and Outcomes, LP-MAESTRO programme of work, funded by the National Institute for Health Research (NIHR) Health Services and Delivery Research Programme (Project number NIHR HS\&DR Project 13/58/08). www.journalslibrary.nihr.ac.uk programmes/hsdr/135808/\#/. The views expressed are those of the authors and not necessarily those of the NIHR or the Department of Health and Social Care

The authors would like to thank Dr Michelle Jones for her assistance with note-taking and transcription, as well as Prof Mike Almond, consultant nephrologist, for his sage advice from an acute clinician perspective. We would like to thank the participants in the focus group and the survey respondents. Finally, we would also like to offer our thanks to the staff of the NHS National Mental Health

Commissioners Network and the Royal College of Psychiatrists for their assistance and support. 
2011; Parsonage et al., 2012). These government guidances were, in turn, strongly influenced by the work of Aitken et al. (2014), who proposed pragmatic CORE24 guidance for how liaison psychiatry services could be configured in English hospitals (Barrett et al., 2015; Aitken et al., 2014). The underpinning work was based, in part, on the Rapid Assessment, Interface and Discharge service developed at Birmingham City Hospital (Tadros et al., 2011), work of colleagues in North West London (Plumridge and Reid, 2012) and also on the developmental and economic ideas proposed by the Centre for Mental Health (Parsonage and Fossey, 2011; Parsonage et al., 2012). Alongside the Royal College of Psychiatrists' quality standards for liaison psychiatry services (Brightey-Gibbons et al., 2017), the CORE24 configuration has become a template for designing services and auditing provision across the NHS.

These guidelines and the accompanying targets for service delivery are specific to England. There have been some commitments to improve the provision of liaison psychiatry services in hospitals in the devolved nations of the UK (Scottish Government, 2017; Llywodraeth Cymru, 2020; Northern Ireland Department of Health, 2020), and improvements have been made (Tahir et al., 2019; Midlands and Lancashire CSU, 2018). However, there are few strategic targets set for liaison psychiatry services per se and health service organisational and structural differences make comparisons with England challenge.

Although much of the weight in the early part of the debate has been placed on the potential for liaison psychiatry services to provide cost savings and efficiencies (Parsonage and Fossey, 2011; Tadros et al., 2011, 2013), and on the overall cost of mental health comorbidities to the NHS (Naylor et al., 2012), little emphasis has been placed on the role, experiences or insights of liaison psychiatry commissioners. This study is a first attempt to understand the views of these staff and to test some of the key emerging themes with health-care managers and medical practitioners.

\section{Background}

Evaluations of liaison psychiatry services have been explored by Wood and Wand (2014) in a systematic review of all published evaluations of inpatient based liaison psychiatry services internationally. This review included 40 articles, spanning 1941 to 2011, the majority of which came from the USA (18 articles) with other research from Australia, Canada, Japan, Saudi Arabia, The Netherlands, Chile and the UK. The review identified very little recent research and significant variability in methodology. In combination with variability in context and service configuration, this leads to a lack of consistency in conclusions regarding the effectiveness of liaison psychiatry services (Wood and Wand, 2014). Overall evidence suggested that liaison psychiatry services were cost-effective, and earlier referral appears to be associated with reduced length of hospital stay. Although, as the authors pointed out, these studies are limited by the lack of a comparison group of patients not receiving liaison psychiatry services.

In the studies reviewed by Wood and Wand, good concordance with management recommendations was shown across liaison psychiatry services. The majority of studies that look at staff satisfaction found support for liaison psychiatry services. However, feedback from patients was variable. These studies were limited by variability in measurement, a lack of details of the specific aspects of the service and no clear benchmark for satisfaction. Furthermore, the authors comment on the importance of timing in collecting feedback, as some studies measured this several months after discharge. Follow-up studies in this context were rare. Evidence from the three studies showed some benefit but was variable in terms of longitudinal outcomes for patients.

Similar criticisms have also been made by Evans et al. (2019) when reviewing the impact of liaison psychiatry in emergency departments. In their reviews, neither Wood and Wand (2014) nor Evans et al. (2019) identified research that had specifically considered the views of commissioners in either the design or effectiveness of liaison psychiatry services. 
In the UK context, recent studies have focussed on evaluating integrated liaison psychiatry services, highlighting the benefits and challenges associated with providing this service. Bestall et al. (2017) discuss the implementation and evaluation of a primary care integrated liaison psychiatry model in three general practitioners (GPS) practices in the UK. Staff and patients reported satisfaction with the service, albeit in a small sample. Challenges identified in this study centred around insufficient staff to deliver the service and to enable evaluation of outcome measures and cost-effectiveness, similar to the findings of Parsonage et al. (2014).

Opmeer et al. (2017) conducted a larger evaluation of liaison psychiatry services in emergency department attendances for self-harm. Extension of liaison psychiatry services hours from 5 to 7 days a week resulted in an increase in the psychosocial assessment of patients from $57 \%$ to $68 \%$, a decrease in waiting times and reduction in the mean cost of patient attendance.

Some of the more recent international studies in this area have focussed on the positive impact of liaison psychiatry on reductions in length of stay (Vulser et al., 2019; Oldham et al., 2019; House et al., 2020), improvements in the emergency department waiting for times (Evans et al., 2019) and overall cost savings benefits (Okoronkwo, 2019). However, there is little consistency in measurement and wide variability in the quality of research design, with a number of authors calling for routine and systematic measurement (Trigwell et al., 2015; Fossey and Parsonage, 2014; Kroll et al., 2020).

\section{Methodology}

We used a mixed-methods approach to address the two overarching questions posed in this research:

Q1. What are the challenges experienced by staff responsible for commissioning of liaison psychiatry services.

Q2. Are these challenges shared by other staff, e.g. hospital managers and mental health clinicians.

\section{Workshop methods and analysis}

A workshop was convened at the NHS Commissioners Mental Health annual conference (12 October 2017) and 12 mental health commissioners opted to participate. The workshop was facilitated by the primary author (MF) with a broad protocol to elicit discussion around the experiences of commissioning liaison psychiatry services. The session was audio-taped and simultaneous field notes/observations were taken. The recording was transcribed and the qualitative data from the workshop was subjected to thematic analysis (Braun and Clarke, 2006) with initial coding undertaken by the primary author. The themes were further tested and scrutinised with a group of subject matter experts from the NHS Commissioners Mental Health group for fidelity and reliability.

\section{Survey methods and analysis}

The agreed themes from the focus group analysis were used to develop a survey (O'Brien, 1993; Secor, 2010). A pilot survey was constructed and tested with a group of commissioners, health service managers and psychiatrists at a large regional general hospital $(n=10)$. Following the principles established by Fowler (2013), amendments and changes for language, design and format were introduced and a version of the survey was produced for distribution. The final version comprised 20 items selected purposively and then placed in random order in the survey. These were specifically drawn from subthemes of the four main themes described in the Results section below. Each item consisted of a statement and an associated Likert scale for respondent scoring. Survey response options 
were assigned a value of 1 (strongly agree) to 5 (Strongly disagree). The survey was distributed, using an opportunistic framework, to commissioners, health service managers and psychiatrists. Respondents were targeted at a national mental health trauma conference and through the online networks of the Royal College of Psychiatrists and NHS commissioners. The 20 item questionnaire can be found in Appendix 2.

Survey responses were analysed using descriptive and inferential statistics in SPSS. Agreement with the 20 statements is presented using percentages for all participants ( $n=$ 98) and stratified by role (clinician, manager or commissioner). Responses were analysed for pairwise group differences by role: clinician $(n=51)$, manager $(n=20)$, commissioner $(n=14)$. Those who chose "other" $(n=11)$ and those who did not specify a role $(n=2)$ were excluded from pairwise group analysis.

The distribution of the data for each question was tested for normality using both a Kolmogorov-Smirnov and Shapiro-Wilks test. The data distribution was found to differ from the normal distribution for all questions $(p<0.001)$. As such, an independent samples Kruskal-Wallis one-way analysis of variance (the non-parametric equivalent of an ANOVA) was used to analyse differences between groups for the different roles.

\section{Results}

\section{Workshop analysis}

Following thematic analysis, four main themes were identified within the workshop transcript:

\section{Funding and commissioning}

\section{Systems and pathways}

\section{Partnership working and co-production}

\section{Data}

\section{Theme A: funding and commissioning}

Commissioners felt that the CORE24 model, was too prescriptive in its approach, especially as the original work to develop this model had been conducted in London and was not necessarily reflective of the needs and experiences of services outside of the capital:

"[...] [the CORE24 model] is [...] too prescriptive and I think that puts a lot of smaller CCGs at a massive disadvantage".

Historically, the growth of liaison psychiatry services in the UK has been idiosyncratic with more mature services being led by a charismatic and resourceful clinician (Parsonage et al., 2012). Commissioners felt that they were placed in a position whereby local need and local nuances were superseded by the need to provide a universal service response:

"All the systems are different, yet we are in a position that we are trying to impose one model which is drawn from small numbers of evaluations from services that have grown from particular circumstances and may not be transferable".

This idiosyncratic design has also historically been coupled with insecure and often unreliable funding. However, over time the situation has improved, probably more as a result of serendipity and local arrangements. As one participant noted [...]:

"[...] liaison service which was originally funded by non-concurrently Winter Pressures money because the local system and whatever the predecessor of A\&E delivery board identified a problem with "people presenting with mental health problems in emergency departments (ED)" which could include anyone who is intoxicated so the money went in and you know I think probably more by accident than design to some extent and it has kind of continued". 
However, commissioners felt that there remains an inequity in the way in which liaison psychiatry services are prioritised across England. It was suggested that this was due to clinical commissioning groups (CCG) prioritising spending dependent upon local need, and where there is a national drive to increase provision, as is the case for liaison psychiatry, there is an emphasis on delivery within the areas that are required by national priorities. These do not always align with the needs and requirements of local areas. Therefore, some of the options for flexibility and responsiveness, that should be integral to CCGs, are unfortunately vetoed by more politically pressing national edicts. These, in turn, are often the gateways to funding:

"I am told by the acute trust that the mental health components of those physical services are very tightly prescribed and very tightly monitored by NHS England which leaves them with very little wiggle room to re-engineer that type of stuff".

Theme B: systems and pathways

Commissioners felt that the delivery of liaison psychiatry services within acute trusts must be considered within the broader delivery of mental health care in the community, and not in isolation. It was suggested that operational changes are needed, rather than a piecemeal approach:

"It is the details in understanding the pathway that is causing the issue, [...] there are lots of very simple operational changes that could be made to improve things".

Commissioners commented that it is not just understanding and changing broader patient care pathways that are important, but often there is a lack of understanding of the types of mental health provision that is currently being provided within acute trusts.

Analysis of the workshop discussion suggests that these services are not well understood from a commissioning perspective, and whether or not they are clinically effective or value for money. Innovative ways of delivering mental health care such as connecting the pathways so that more improving access to psychological therapy (IAPT) service activity can be delivered within the acute hospital setting, were suggested as potential solutions to deliver cost savings:

"Health psychology function in our acute hospital costs a lot of money, I am sure they do a very good job but it is not measured and if we connect that up with IAPTs we probably don't need to train a load more practitioners in long term conditions, etc".

Although the drive within the FYFV for mental health is the delivery of a robust liaison psychiatry offer in emergency departments, commissioners articulated that the most cost savings could be made elsewhere in the pathway:

"Well, the big numbers are in the back end of the acute hospitals aren't they? It's not acute mental health at all, its frail older people".

Theme C: partnership working and co-production

Commissioners report that without clear instruction or mandate for co-production, achieving partnership working remains one of their biggest challenges:

"I find it very difficult to get into a co-commissioning dialogue with either my acute or mental health trust on [liaison psychiatry] that really is meaningful"

There is some enthusiasm amongst commissioners for an accountable care system approach [...]:

"[...] I think actually moving towards the ACS (Accountable Care System) model and I think that is going to help so mental health, social services and the acute trust will start pooling resources and have shared outcomes so I am a big believer in that". 
But, there remain challenges with territorialism and protectionism [...]:

"[...] we reviewed our [mental health] services two years ago and they are performing really well and actually our clinical leads didn't want to hand over that shared commissioning arrangement"

Theme D: data

Lack of data, fragmentation of records and lack of continuity would appear to be one of the most challenging areas for liaison psychiatry commissioners. Alongside the clinical and time management challenges, it is also very difficult for commissioners to access data to effectively understand the impact of these services:

"[...] you can't track to what extent they're people who are impacting on acute hospital and [...] secondary care, mental health case-loads because you have all of the information sharing issues there".

Commissioners argued that obtaining good data on mental health admissions or more importantly on patients who have a co-morbid mental health presentation, is more to do with the quality of the initial coding of patients:

"what you actually get out is only as good as the coding that happens in ED".

Having better quality data would empower commissioners to make more informed decisions about service provision across the entire patient pathway [...]:

"[...] the sheer number of ED breaches associated with mental health [...] trying to understand the problem of how our patients get there in the first place and then really robustly answer the question 'what proportion of people seen by Liaison psychiatry had a medical problem that necessitated their attendance at ED'"?

\section{Survey results}

The table in Appendix 1 shows the median responses for each of the 20 questions, stratified by a group and the results of the Kruskal-Wallis tests. Group differences were found for questions 3, 5, 12 and 16 only and pairwise comparisons showed a significant difference between clinicians and commissioners responses for each of these questions. Even when there were differences these tended to be on the strength of the response rather than divergence, except in relation to outcome measures (Question 5) which is discussed below. There was a convergence in responses to all the other questions indicating a broad agreement with the statements.

The majority of respondents disagreed or strongly disagreed (91.8\%) that community mental health services are coping well with demand (Figure 1). However, a significant difference was found between groups, $\left(\chi^{2}(2)=8.715, p=0.013\right)$ with a pairwise comparison indicating a difference. commissioner groups only. A higher percentage of clinicians strongly disagreed (62.7\%) with this statement compared to commissioners (14.3\%).

The large majority of respondents agreed or strongly agreed (83.2\%) that liaison psychiatry can save the acute trust money (Figure 2). However, a significant difference was found between groups, $\left(\chi^{2}(2)=7.447, p=0.024\right)$ with a pairwise comparison indicating a difference between the clinicians and commissioner groups only. A higher percentage of clinicians agreed or strongly agreed (91.5\%) with this statement compared to commissioners (64.3\%) (Question 5). Additionally, clinicians were more likely to strongly agree $(65.3 \%)$ compared to commissioners (28.6\%).

For clinical outcome measurement (Question 12; Figure 3), a significant difference was found between groups $\left(\chi^{2}(2)=6.018, p=0.049\right)$. Pairwise comparison indicated a difference between the clinicians and commissioner groups only ( $p=0.037$ ). Indeed, a 


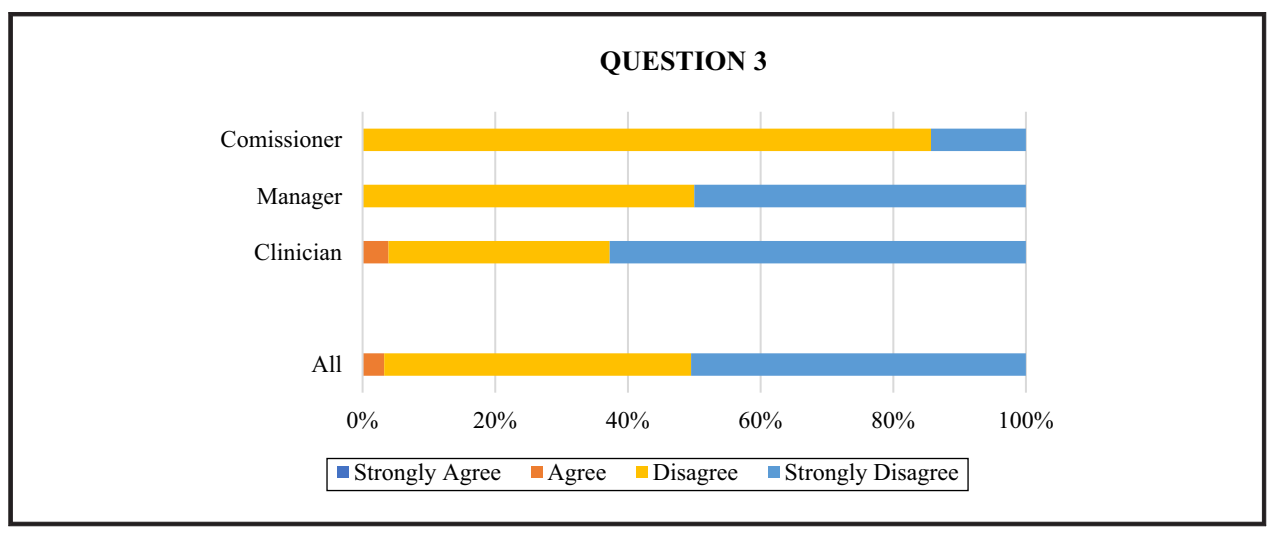

\section{Figure 2 Responses to Question 5: "Liaison psychiatry can save the acute trust money"}

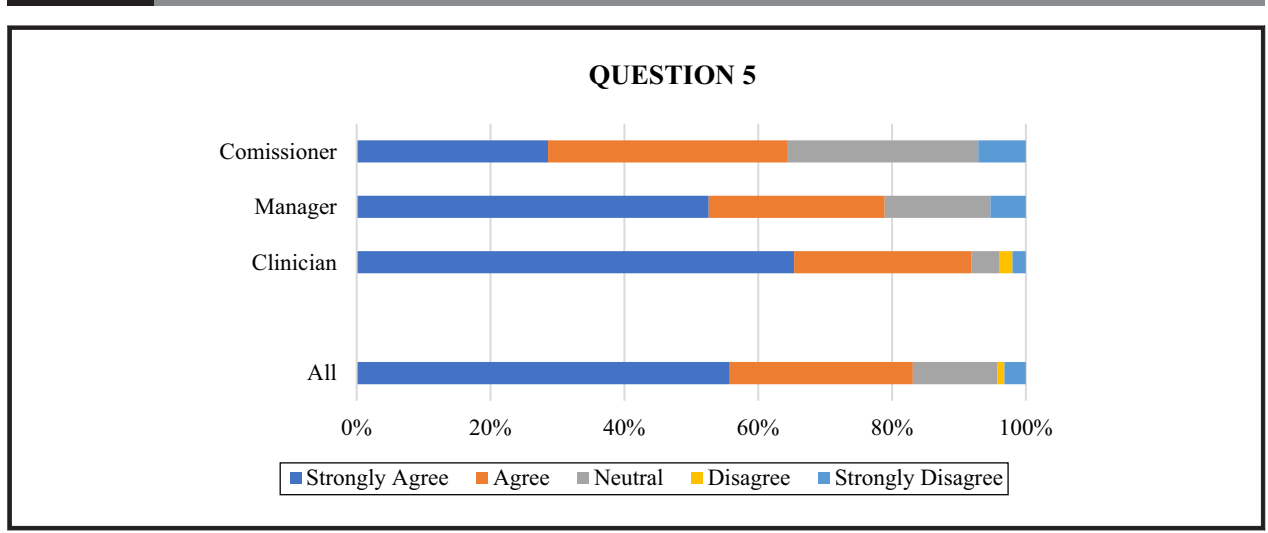

\section{Figure 3 Responses to Question 12: "Clinical outcome measures are routinely collected in liaison psychiatry services"}

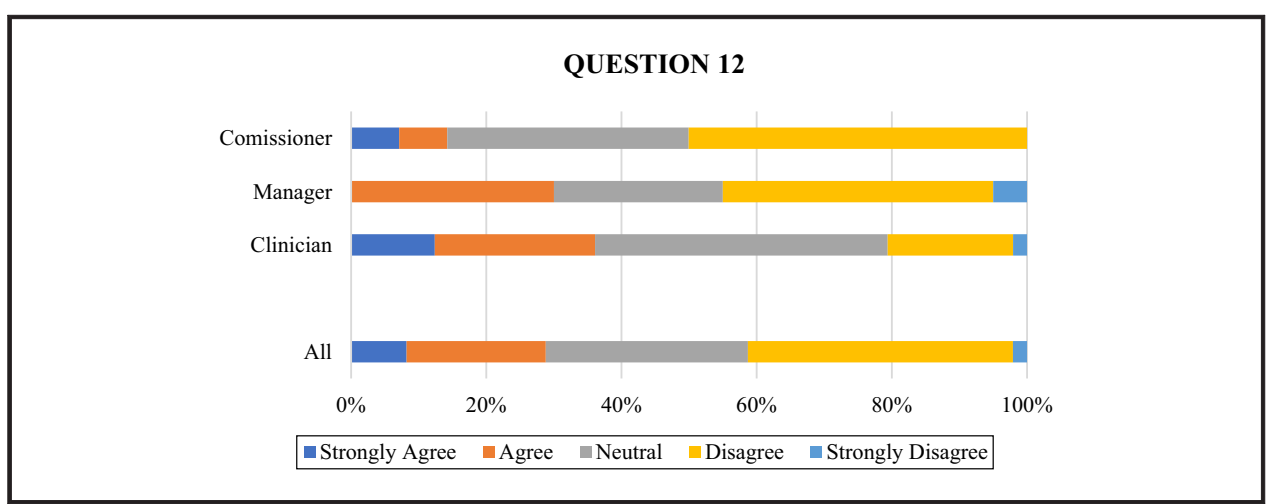

larger proportion of commissioners disagreed or strongly disagreed with this statement (85.7\%) compared to clinicians (69.1\%) suggesting commissioners were more likely to disagree with the statement that patient outcome measures are routinely collected.

Similarly when asked about the collection of patient experience measures (Question 16; Figure 4) a significant difference was found between groups $\left(\chi^{2}(2)=8.64, p=0.013\right)$. 


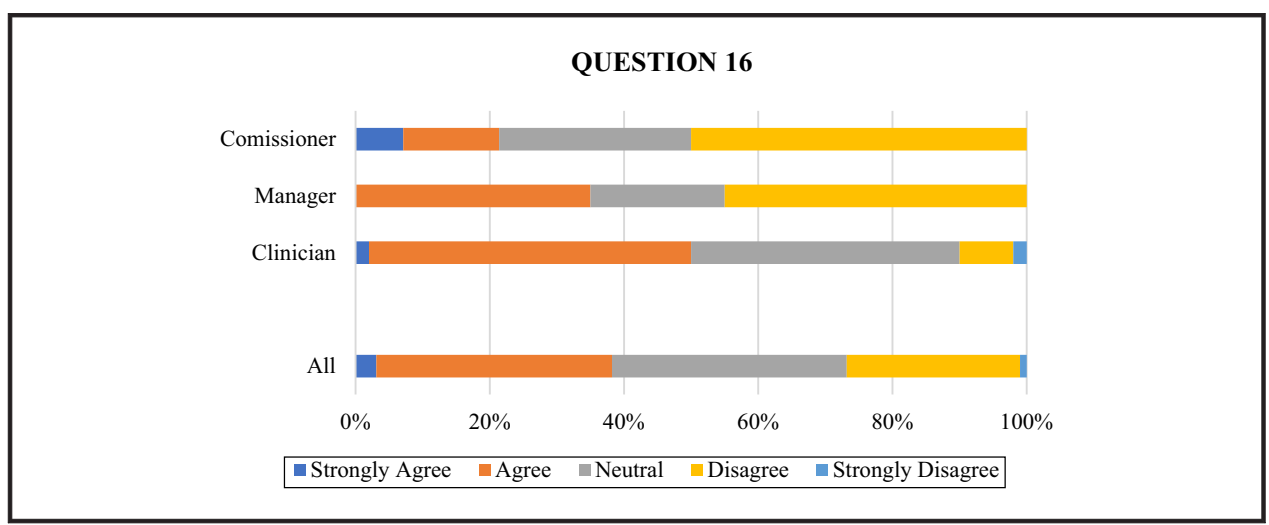

Pairwise comparison indicated a difference between the clinicians and commissioner groups only, $p=0.04$ and indicated that clinicians are more likely to agree that patient data is routinely collected in liaison psychiatry services compared to commissioners. Indeed, clinicians most often agreed with this statement (48) and commissioners most often disagreed (50\%).

\section{Discussion}

There was general agreement from survey respondents that money should be ring-fenced for liaison psychiatry services, but spot-purchasing of services was not a good idea. There is research that provides a compelling argument about the economic burden of mental and physical co-morbidities (Bermingham et al., 2010; Naylor et al., 2012), and suggests that liaison psychiatry services can save money for acute trusts (Parsonage and Fossey, 2011; Tadros et al., 2013). The review by Wood and Wand (2014) and recent French (Yrondi et al., 2016) and Canadian (Okoronkwo, 2019) studies have identified similar economic benefits. However, we identified that commissioners were less likely to agree that liaison psychiatry services can save acute trusts money, compared to clinicians. Although the drive within the FYFV for mental health is the delivery of a robust liaison psychiatry offer in emergency departments, commissioners felt that the most cost savings could be made elsewhere in the pathway.

The lack of clarity of the different mechanisms for commissioning psychology or other mental health services in acute hospitals was discussed in the workshop. Commissioners appeared frustrated that the approach to delivering mental health and psychological interventions continues to be idiosyncratic and often driven by the clinical interests of consultant psychiatrists. There was a perceived lack of coordination within and across clinical departments, with the potential for a number of complications. Firstly, there is no clear understanding of the net cost of delivering mental health interventions across the hospital. There is also no way of accurately recording the type and number of patients that receive interventions, and what these interventions and outcomes are. This discrepancy between clinician and commissioner perspectives is supported by House et al. (2020), who reports that:

- clinicians believe they collect outcomes routinely because they monitor how individual patients do, and consequently believe they save money because they see the evidence in cases where they change the trajectory of care; and

- commissioners are less convinced because they do not see the dramatic length of stay changes claimed for the UK rapid assessment interface and discharge (RAID) liaison psychiatry model (Tadros et al., 2013) but they do not see the convincing routine collection of outcomes for whole services. 
Secondly, some concerns were raised by the commissioners about clinical governance. Who is providing supervision and clinical governance for these disparate clinicians? The Royal College of Psychiatrist's guidelines for liaison psychiatry accreditation proposes that appropriate governance structures should be an integral element of any service (BrighteyGibbons et al., 2017). Mental health clinicians such as psychologists, working within outpatient clinics may not have any formal connection with liaison psychiatry teams working in the hospital. Stronger arrangements for co-ordination and integration of acute mental health service (liaison psychiatry services, clinical psychology, health psychology, IAPT) should be considered.

Arrangements to jointly commission liaison psychiatry services were seen as positive by respondents and, although not tested in the survey, commissioners in the workshop felt that the move towards integrated care systems may be potentially beneficial for liaison psychiatry services.

There is no previous UK research specifically pertaining to the commissioning of liaison psychiatry services. A survey of liaison psychiatry services in England found widespread availability of these services in an acute hospital. Walker et al. (2018) suggested that while a significant increase in liaison psychiatry has been seen over the past two decades, there is still a lack of outpatient clinics, non-acute care and long term management. Walker et al. (2018) also proposed the following implications for the commissioning of liaison psychiatry services; liaison psychiatry teams were poorly resourced in comparison to published recommendations, national coordination of services is lacking and provision of longer-term outpatient care is poor. Furthermore, House et al. (2018) highlight the importance of regularly reviewing targets, considering the wider impact of the service and being mindful of external changes to health-care in relation to commissioning liaison psychiatry services.

Respondents to the survey agreed that psychological medicine requires strong clinical governance and, the majority of respondents felt that spot-purchasing of psychological medicine services in acute hospital outpatient clinics was not a good idea. Despite some evidence suggesting that provision in primary care has an impact on outcomes for patients and GP and has been shown to be cost-effective (Parsonage et al., 2014), only 59.4\% of respondents agreed that liaison psychiatry should be integrated into community service.

A large majority of the respondents agreed (82.6\%) than patients in mental health crises were being signposted to emergency departments, despite the concerns raised about the appropriateness of using EDs as a place of safety (Merrifield, 2017). The commissioning dashboard (NHS, 2018) is driving the commissioning of liaison psychiatry provision in EDs, and some of the challenges experienced in EDs may eventually be alleviated through the application of Royal College of Emergency Medicine (RCEM) guidelines (Swires-Hennessy and Hayhurst, 2017).

Additionally, a majority of respondents agreed that GPs were not equipped to manage patients in mental health crises (87.2\%) and that acute staff are not trained to understand mental illnesses (80.9\%). The respondents reported that there appeared to be an ambiguity or non sequitur in the current system of provision, where all respondents agree that GPs are not providing optimal care for these patients and signposting them to ED for interventions that should be provided in primary care. This is despite the fact that ED staff do not have adequate training to meet the needs of these patients. As one commissioner commented [...] "sometimes patients are being sent to ED to get a Zopiclone out-of-hours prescribing service, the misuse of ED".

Commissioners felt that partnership working remains one of their biggest challenges. This is despite political momentum towards integrated care services, which is gradually being introduced into areas across England (NHS, 2020).

There was agreement that community services were not coping well with demand (91.8\%). However, a significant difference was found between the clinicians and commissioner 
groups, $\left(\chi^{2}(2)=8.715, p=0.013\right)$, suggesting that clinicians more strongly disagreed with the statement that "community mental health services are coping well with demand" than commissioners. Although all groups agreed that community services were not coping, the survey results suggested that this was felt more acutely by clinical staff, similar to findings by the trade union Unison (Unison, 2017).

All respondents agreed that accessing mental health data in acute trusts presents a challenge. The challenges of poor quality data have been identified by both the RCEM (Swires-Hennessy and Hayhurst, 2017) and the Royal College of Psychiatrists (BrighteyGibbons et al., 2017). With only a few exceptions in England [1], liaison psychiatry is provided by mental health providers within the general hospital leading to data system incompatibility with liaison psychiatry staff recording in multiple notes (Parsonage et al., 2012). This may become worse as specialist services are consolidated on fewer sites. Without access to accurate mental health records, it is difficult to undertake a comprehensive assessment. Swires-Hennessy and Hayhurst (2017) also point out that busy ED staff do not always record mental health presentations, focussing on physical injuries. This partial clinical picture may impact decision-making further along the patient pathway.

Problems with accessing basic information about liaison psychiatry performance were also identified by all respondents. Gathering data on performance appears to be idiosyncratic and driven by a requirement to justify effectiveness to funders (Parsonage et al., 2012), rather than as a tool for service development and improvement. Nevertheless, a set of principles for data collection has been developed to aid services (Trigwell et al., 2015; Fossey and Parsonage, 2014).

\section{Limitations}

This was a small preliminary study and only one commissioner workshop was held with 12 attendees. While the analysis and results were shared with an expert group to ensure fidelity and reliability, a broader commissioner view would have been preferable. There were 98 respondents to the questionnaire, of whom the majority were clinicians. Using an opportunistic framework, the sample may not be representative. The lead author (MF) was also conscious of confirmation bias as he has been instrumental in a number of previous liaison psychiatry studies (Parsonage and Fossey, 2011; Parsonage et al., 2012; Fossey and Parsonage, 2014) albeit not with a focus on the experiences of commissioners. Additionally, multiple pairwise comparisons were conducted during the analysis of the survey responses. This increases the risk that a significant result (i.e. those in which $p$ values are smaller than 0.05 ) was simply found by chance. As such, caution should be exercised in the interpretation of $p$ values that are close to the 0.05 threshold.

\section{Conclusion}

This research is the first time that commissioners have been interviewed about their views on the delivery of liaison psychiatry services, and the outcomes of the subsequent analysis tested with other health care professionals.

It is evident in the analysis of data from the workshop that the themes identified, namely, funding and commissioning; systems and pathways; partnership working and coproduction and; data, are not exclusive, but inextricably linked. It would appear that improvements in all of these four key areas are essential to enhance better commissioning decision-making. Furthermore, this work has identified that commissioners of liaison psychiatry services are not routinely consulted or involved in design or monitoring. Developing better communication channels, including performance data, between all those involved in the development and delivery of liaison psychiatry services would inevitably help to inform where on the health care pathway services should best be deployed to improve patient outcomes. 
While it is recognised that further research with larger sample size is needed to confirm whether the results of this observational study are representative of the experiences and views of commissioners and other health professionals, a number of areas for service improvement are made drawn from the findings (Fossey and Godier-McBard, 2020):

- Commissioners, hospital managers and clinicians should work collaboratively on the planning of liaison psychiatry services.

- Acute hospital-based liaison psychiatry services should adopt the outcome measurement framework proposed by the Royal College of Psychiatrists (Trigwell et al., 2015) and the data collected, alongside performance data, should be shared regularly with commissioners.

- Acute hospitals should undertake a thorough audit of all of their mental health provision. This audit should focus on identifying where services are operating in isolation and consider the clinical governance implications. The resource consequences of spotpurchased mental health services should be examined and shared with commissioners.

- Access to patients' mental health records, especially in emergency departments needs to be improved.

- An interprofessional learning module should be developed to upskill both acute and community-based staff in the clinical management of mental health and long-term conditions and medically unexplained symptoms. This could draw on existing work such as the Royal College of Psychiatrists CPD module" psychiatry for the modern physician: common psychiatric presentations in general medicine"(Royal College of Psychiatrists, 2020).

\section{Note}

1. For example, provision at the John Radcliffe Hospital in Oxford, where in-patient acute services are commissioned by the JR and services in ED are provided by the local mental health trust.

\section{References}

Aitken, P. Robens, S. and Emmens, T. (2014), "Developing models for liaison psychiatry Services Guidance", Strategic Clinical Network for Mental Health, Dementia and Neurological Conditions South West.

Barrett, J., Aitken, P. and Lee, W. (2015), "Report of the 2nd annual survey of liaison psychiatry in England", Prepared for NHS England and the National Collaborating Centre for Mental Health, part of the Royal College of Psychiatrists, available at: www.rcpsych.ac.uk/pdf/CALC_LIA2015WilliamLee1.pdf (accessed 14 February 2019).

Bermingham, S.L., Cohen, A., Hague, J. and Parsonage, M. (2010), "The cost of somatisation among the working age population in England for the year 2008-2009", Mental Health in Family Medicine, Vol. 7 No. 2, pp. 71-84.

Bestall, J., Siddiqi, N., Heywood-Everett, S., Freeman, C., Carder, P., James, M., Kennedy, B., Moulson, A. and House, A. (2017), "New models of care: a liaison psychiatry service for medically unexplained symptoms and frequent attenders in primary care", BJPsych Bulletin, Vol. 41 No. 6, pp. 340-344.

Braun, V. and Clarke, V. (2006), "Using thematic analysis in psychology", Qualitative Research in Psychology, Vol. 3 No. 2, pp. 77-101.

Brightey-Gibbons, F., Patterson, E., Rhodes, E., Ryley, A. and Hodge, S. (Eds) (2017), Quality Standards for Liaison Psychiatry Services, RCPsych.

Evans, R., Connell, J., Ablard, S., Rimmer, M., O'Keeffe, C. and Mason, S. (2019), "The impact of different liaison psychiatry models on the emergency department: a systematic review of the international evidence", Journal of Psychosomatic Research, Vol. 119, pp. 53-64. 
Fellow-Smith, E., Moss-Morris, R., Tylee, A., Fossey, M., Cohen, A. and Nixon, T. (2012), Investing in Emotional and Psychological Wellbeing for Patients with Long-Term Conditions, NHS Confederation, London.

Fossey, M. and Godier-Mcbard, L. (2020), Commissioning Liaison Psychiatry Services, Centre for Mental Health, London.

Fossey, M. and Parsonage, M. (2014), Outcomes and Performance in Liaison Psychiatry, Centre for Mental Health, London.

Fowler, F.J. (2013), Survey Research Methods, Sage publications, CA.

Hague, J. and Fossey, M. (2012), "Healthcare commissioning and contracting", in Markar, H. and O'sullivan, G. (Eds), Medical Management: A Survival Guide, CRC Press, London.

House, A., West, R., Smith, C., Tubeuf, S., Guthrie, E. and Trigwell, P. (2020), "The effect of a hospital liaison psychiatry service on inpatient lengths of stay: interrupted time series analysis using routinely collected NHS hospital episode statistics", BMC Psychiatry, Vol. 20 No. 1, p. 27.

House, A., Guthrie, E., Walker, A., Hewsion, J., Trigwell, P., Brennan, C., Crawford, M., Murray, C.C., Fossey, M. and Hulme, C. (2018), "A programme theory for liaison mental health services in England", BMC Health Services Research, Vol. 18 No. 1, p. 742.

Kroll, D.S., Gopal, A., Kimmel, R.J., Mattson, J., Beizai, K. and Danovitch, I. (2020), Performance Measurement Tools for Consultation-Liaison Psychiatry Services Must Consider Feasibility, Elsevier.

Llywodraeth Cymru (2020), "Together for mental health delivery plan: 2019-22"

Merrifield, N. (2017), "A\&E 'unacceptable place' for mental health patients in crisis, say RCN members", Nursing Times, 16 May 2017.

Midlands and Lancashire CSU (2018), "Evaluation of an integrated mental health liaison service (RAID): prepared for the Northern health and social care trust"

Naylor, C., Parsonage, M., Mcdaid, D., Knapp, M., Fossey, M. and Galea, A. (2012), Long-Term Conditions and Mental Health: The Cost of co-Morbidities, The Kings Fund, London.

Naylor, C., Imison, C., Addicott, R., Buck, D., Goodwin, N., Harrison, T., Ross, S., Sonola, L., Tian, Y. and Curry, N. (2015), Transforming Our Health Care System: Ten Priorities for Commissioners, The Kings Fund, London.

NHS England (2020), NHS Long Term Plan, available at: www.longtermplan.nhs.uk/ (accessed September 2020).

NHS (2018), "Mental health five year forward view dashboard", available at: www.england.nhs.uk/ publication/mental-health-five-year-forward-view-dashboard/. (accessed 11 January 2019).

NHS (2020), "Integrated care systems", available at: www.england.nhs.uk/integratedcare/integratedcare-systems/ (accessed 25 March 2020)

Northern Ireland Department of Health (2020), Department of Health Mental Health Action Plan.

O’Brien, K. (1993), "Using focus groups to develop health surveys: an example from research on social relationships and AIDS-preventive behavior", Health Education Quarterly, Vol. 20 No. 3, pp. 361-372.

Okoronkwo, E. (2019), "Estimation of costs-savings and improved patient outcomes of implementing a Consultation-Liaison service at health sciences North", Open Journal of Psychiatry, Vol. 09 No. 03, p. 220.

Oldham, M.A., Chahal, K. and Lee, H.B. (2019), "A systematic review of proactive psychiatric consultation on hospital length of stay", General Hospital Psychiatry, Vol. 60

Opmeer, B.C., Hollingworth, W., Marques, E.M., Margelyte, R. and Gunnell, D. (2017), "Extending the liaison psychiatry service in a large hospital in the UK: a before and after evaluation of the economic impact and patient care following ED attendances for self-harm", BMJ Open, Vol. 7 No. 8, p. e016906.

Parsonage, M. and Fossey, M. (2011), Economic Evaluation of a Liaison Psychiatry Service, Centre for Mental Health, London.

Parsonage, M., Fossey, M. and Tutty, C. (2012), Liaison Psychiatry in the Modern NHS, Centre for Mental Health, London.

Parsonage, M., Hard, E. and Rock, B. (2014), Managing Patients with Complex Needs: evaluation of the City and Hackney Primary Care Psychotherapy Consultation Service, Centre for Mental Health, London. 
Plumridge, N. and Reid, S. (2012), "Liaison psychiatry can bridge the gap", Health Service Journal, Vol. 6, pp. 24-26.

Roland, M. and Rosen, R. (2011), "English NHS embarks on controversial and risky market-style reforms in health care", New England Journal of Medicine, Vol. 364 No. 14, pp. 1360-1366.

Royal College of Psychiatrists (2020), "Psychiatry for the modern physician: common psychiatric presentations in general medicine", available at: www.psychiatrycpd.co.uk/rcpmodules.aspx (accessed 23 March 2020).

Scottish Government (2017), "Mental health strategy 2017-2027",

Secor, A. (2010), "Social surveys, interviews, and focus groups", in Gomez, B. and Jones, J. (Eds), Research Methods in Geography, John Wiley \& Sons, Chichester, West Sussex, 3, pp. 194-205.

Swires-Hennessy, K. and Hayhurst, C. (2017), Mental Health in Emergency Departments: A Toolkit for Improving Care, The Royal College of Emergency Medicine.

Tadros, G., Salama, R., Mustafa, N., Pannell, R. and Balloo, S. (2011), RE: The Rapid Assessment Interface and Discharge Team, City Hospital Birmingham: Evaluation Report December 2009 September 2010 (Latest draft).

Tadros, G., Salama, R.A., Kingston, P., Mustafa, N., Johnson, E., Pannell, R. and Hashmi, M. (2013), "Impact of an integrated rapid response psychiatric liaison team on quality improvement and cost savings: the Birmingham RAID model", The Psychiatrist, Vol. 37 No. 1, pp. 4-10.

Tahir, T.A., Watkins, A., Slack, P., Chick, P., Lee, W. and Gray, A. (2019), "Liaison psychiatry services in Wales", BJPsych Bulletin, Vol. 43 No. 1, pp. 17-20.

Trigwell, P. Kustow, J. Santhouse, A. Gopinath, R. Aitken, P. Reid, S. Wilson, N. and Martin, K. (2015), "Framework for routine outcome measurement in liaison psychiatry (from-LP)", Royal College of Psychiatrists, London, available at: www.rcpsych.ac.uk

UNISON (2017), "Working in mental health: the problems in five charts", available at: www.unison.org.uk/ news/ps-data/2017/10/working-mental-health-problems-five-charts/ (accessed 25 March 2020).

Vulser, H., Vinant, V., Lanvin, V., Chatellier, G., Limosin, F. and Lemogne, C. (2019), "Association between the timing of consultation-liaison psychiatry interventions and the length of stay in general hospital", The British Journal of Psychiatry, pp. 1-6, doi: 10.1192/bjp.2019.233.

Walker, A., Barrett, J.R., Lee, W., West, R.M., Guthrie, E., Trigwell, P., Quirk, A., Crawford, M.J. and House, A. (2018), "Organisation and delivery of liaison psychiatry services in general hospitals in England: results of a national survey", BMJ Open, Vol. 8 No. 8, p. e023091.

Wood, R. and Wand, A.P. (2014), "The effectiveness of consultation-liaison psychiatry in the general hospital setting: a systematic review", Journal of Psychosomatic Research, Vol. 76 No. 3, pp. 175-192.

Yrondi, A., Petiot, D., Arbus, C. and Schmitt, L. (2016), "Economic impact of consultation-liaison psychiatry in a French university hospital Centre", L'Encephale, Vol. 42 No. 1, pp. 112-115.

\section{Author affiliations}

Matt Fossey and Lauren Godier-McBard are both based at the Faculty of Health, Education, Medicine and Social Care, Veterans and Families Institute for Military Social Research, Anglia Ruskin University, Chelmsford, UK.

Elspeth A. Guthrie, Jenny Hewison, Peter Trigwell, Chris J. Smith, and Allan O. House are all based at the Leeds Institute of Health Sciences, University of Leeds, Leeds, UK. 


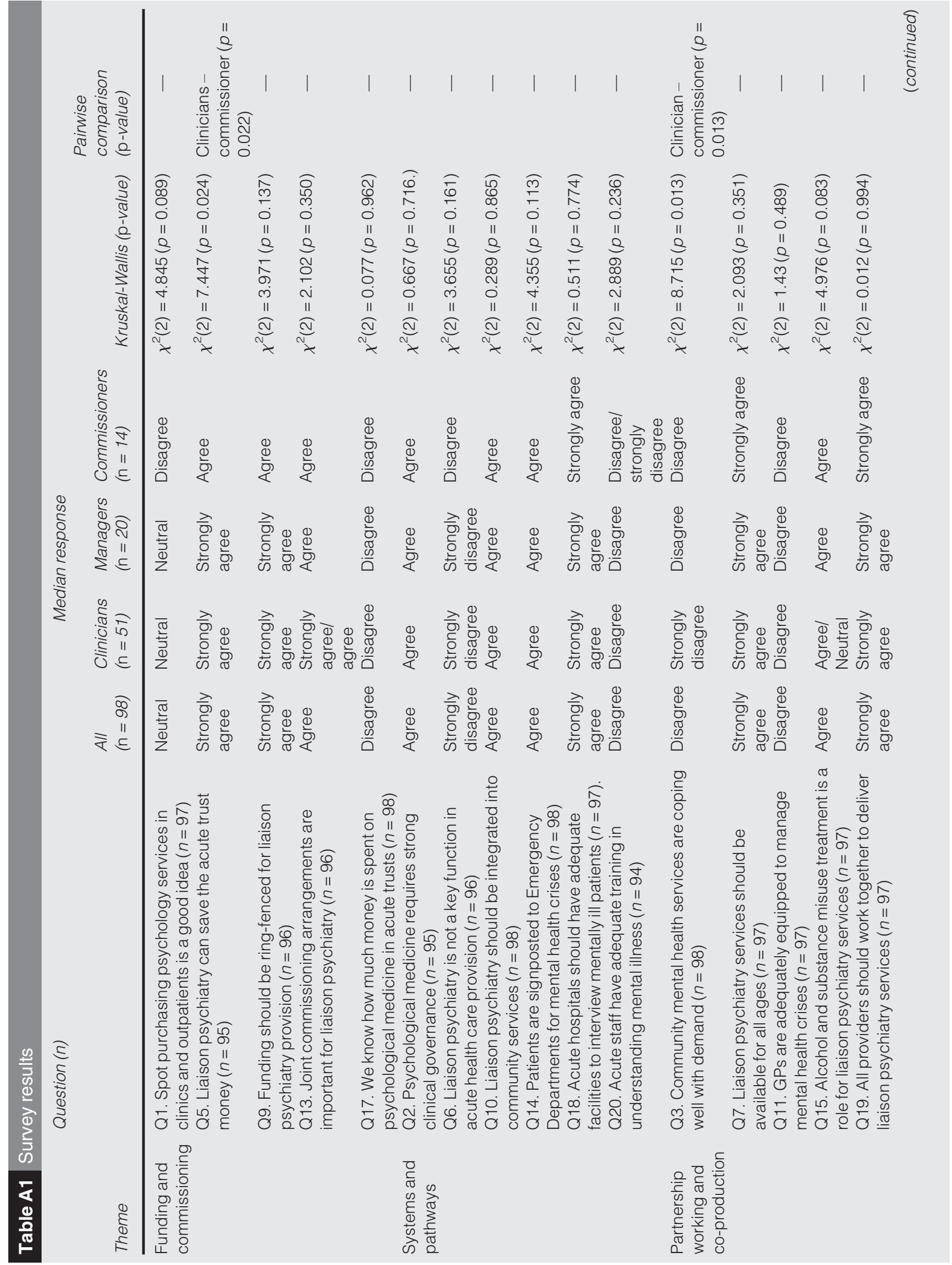




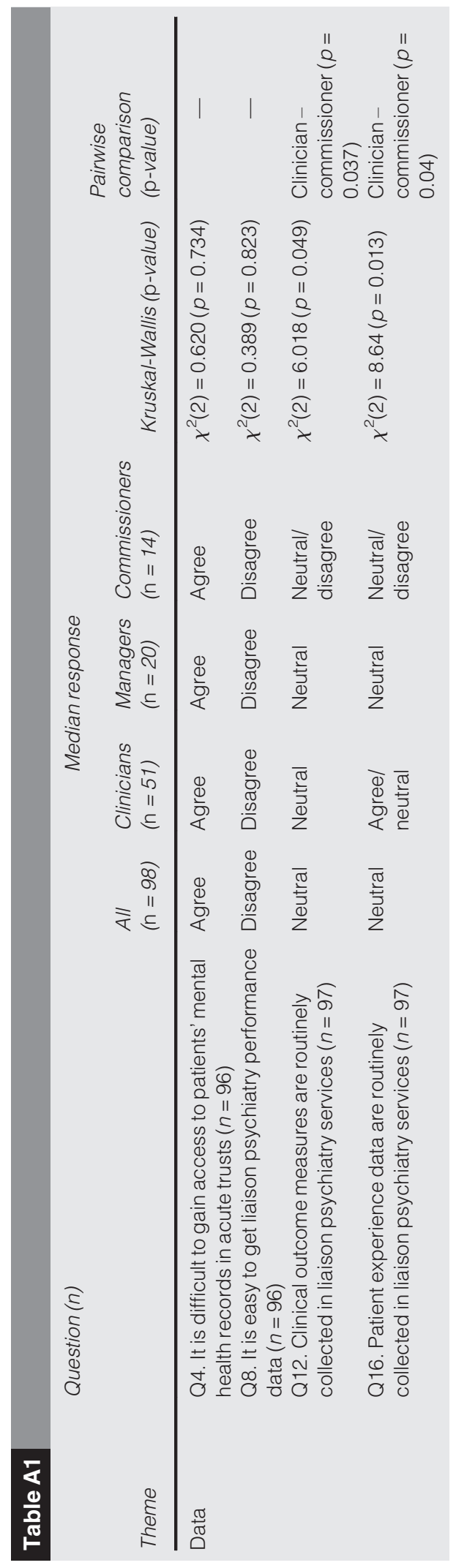

\begin{tabular}{l|l|l} 
VOL. 25 NO. 42020 & MENTAL HEALTH REVIEW JOURNAL & PAGE 315
\end{tabular} 


\section{Appendix 2}

\section{Table A2 20-Item questionnaire}

\begin{tabular}{lrl} 
Theme & $\#$ & Question \\
\hline Funding and commissioning & 1 & Spot purchasing psychology services in clinics and outpatients is a good idea \\
& 5 & Liaison psychiatry can save the acute trust money \\
& 9 & Funding should be ring-fenced for liaison psychiatry provision \\
Systems and pathways & 13 & Joint commissioning arrangements are important for liaison psychiatry \\
& 2 & We know how much money is spent on psychological medicine in acute trusts \\
& 6 & Liaison psychiatry is not a key function in acute health care provision \\
& 10 & Liaison psychiatry should be integrated into community services \\
Partnership working and co-production & 14 & Patients are signposted to Emergency Departments for mental health crises \\
& 18 & Acute hospitals should have adequate facilities to interview mentally ill patients \\
& 20 & Acute staff have adequate training in understanding mental illness \\
& 3 & Community mental health services are coping well with demand \\
& 7 & Liaison psychiatry services should be available for all ages \\
Data & 11 & GPs are adequately equipped to manage mental health crises \\
& 15 & Alcohol and substance misuse treatment is a role for liaison psychiatry services \\
& 4 & All providers should work together to deliver liaison psychiatry services \\
& 8 & It is difficult to gain access to patients' mental health records in acute trusts
\end{tabular}

\section{Corresponding author}

Matt Fossey can be contacted at: matt.fossey@aru.ac.uk

For instructions on how to order reprints of this article, please visit our website: www.emeraldgrouppublishing.com/licensing/reprints.htm

Or contact us for further details: permissions@emeraldinsight.com 